\title{
Aplicabilidade da Tecnologia Assistiva para pessoas com lesão medular: Uma revisão integrativa
}

\author{
Applicability of Assistive Technology for people with spinal cord injury: An integrative review \\ Aplicabilidad de la tecnología de asistencia para personas con lesión de la médula espinal: Una \\ revisión integradora
}

Recebido: 23/04/2021 | Revisado: 02/05/2021 | Aceito: 30/06/2021 | Publicado: 03/07/2021

\author{
Hilmara Ferreira da Silva \\ ORCID: https://orcid.org/0000-0001-5442-8561 \\ Universidade Federal do Estado do Rio de Janeiro, Brasil \\ E-mail: silvahilmara@gmail.com \\ Juliane Ferreira da Silva \\ ORCID: https://orcid.org/0000-0002-2621-8126 \\ Universidade Federal do Estado do Rio de Janeiro, Brasil \\ E-mail: julianeferreiradasilva51@gmail.com \\ Vanessa Vianna Cruz \\ ORCID: https://orcid.org/0000-0003-3564-0457 \\ Universidade Federal do Estado do Rio de Janeiro, Brasil \\ E-mail: vanessavianna2005@yahoo.com.br \\ Nébia Maria Almeida de Figueiredo \\ ORCID: https://orcid.org/0000-0003-0880-687X \\ Universidade Federal do Estado do Rio de Janeiro, Brasil \\ E-mail: nebia43@gmail.com \\ Aline Coutinho Sento Sé \\ ORCID: https://orcid.org/0000-0001-9301-0379 \\ Universidade Federal do Estado do Rio de Janeiro, Brasil \\ E-mail: aline2506@hotmail.com \\ Wiliam César Alves Machado \\ ORCID: https://orcid.org/0000-0002-4325-7143 \\ Universidade Federal do Estado do Rio de Janeiro, Brasil \\ E-mail: wily.machado@gmail.com
}

\begin{abstract}
Resumo
O presente estudo visa apresentar a aplicabilidade da Tecnologia Assistiva para o desempenho das atividades cotidianas e promoção da autonomia funcional em pessoas com lesão medular. Trata-se de uma revisão integrativa realizada nas seguintes bases de dados: Lilacs, SCiELO, Ibecs, Bdenf, e PubMed no período de 2015 a 2020 , utilizando os descritores: Tecnologia Assistiva; Traumatismos da Medula Espinhal; Classificação Internacional de Funcionalidade, Incapacidade e Saúde; Atividades Cotidianas e Reabilitação Física. Foram adotados como critérios de inclusão as publicações disponíveis em português, espanhol e inglês, publicados nos referidos bancos de dados, no período de 2015 a 2020. No total foram incluídas 15 publicações internacionais em que emergiram as seguintes categorias: Tecnologia assistiva no desempenho das atividades cotidianas e Tecnologia assistiva na promoção da autonomia funcional. A partir da análise dos artigos foi possível observar que a Tecnologia Assistiva teve um papel fundamental para o desempenho das atividades cotidianas na pessoa com lesão medular, já que permitiu tanto a realização de tarefas antes limitadas por sua condição quanto favoreceu a promoção da autonomia funcional.

Palavras-chave: Tecnologia assistiva; Traumatismos da medula espinhal; Atividades cotidianas; Classificação internacional de funcionalidade, Incapacidade e saúde; Reabilitação física.
\end{abstract}

\begin{abstract}
This study aims to present the applicability of Assistive Technology for the performance of daily activities and promotion of functional autonomy in people with spinal cord injury. This is an integrative review carried out in the following databases: Lilacs, SCiELO, Ibecs, Bdenf, and PubMed from 2015 to 2020, using the descriptors: Assistive Technology; Spinal Cord Injuries; International Classification of Functioning, Disability and Health; Daily Activities and Physical Rehabilitation. Publications available in Portuguese, Spanish and English, published in the aforementioned databases, from 2015 to 2020 were adopted as inclusion criteria. In total, 15 international publications were included in which the following categories emerged: Assistive technology in the performance of activities and Assistive Technology in the promotion of functional autonomy. From the analysis of the articles, it was possible to observe that Assistive Technology played a fundamental role in the performance of daily activities in people with
\end{abstract}


spinal cord injury, as it allowed both the performance of tasks previously limited by their condition and favored the promotion of functional autonomy.

Keywords: Assistive technology; Spinal cord injuries; Daily activities; International classification of functioning, disability and health; Physical rehabilitation.

\section{Resumen}

Este estudio tiene como objetivo presentar la aplicabilidad de la Tecnología Asistiva para el desempeño de las actividades diarias y la promoción de la autonomía funcional en personas con lesión medular. Se trata de una revisión integradora realizada en las siguientes bases de datos: Lilacs, SCiELO, Ibecs, Bdenf y PubMed de 2015 a 2020 , utilizando los descriptores: Assistive Technology; Lesiones de la médula espinal; Clasificación Internacional de Funcionamiento, Discapacidad y Salud; Actividades Diarias y rehabilitación física. Se adoptaron como criterios de inclusión las publicaciones disponibles en portugués, español e inglés, publicadas en las bases de datos antes mencionadas, de 2015 a 2020. En total, se incluyeron 15 publicaciones internacionales en las que surgieron las siguientes categorías: Tecnología de apoyo en la realización de actividades y Tecnología de apoyo en la promoción de la autonomía funcional. Del análisis de los artículos se pudo observar que la Tecnología Asistiva jugó un papel fundamental en el desempeño de las actividades Diarias en personas con lesión medular, ya que permitió tanto la realización de tareas previamente limitadas por su condición como favoreció la promoción de autonomía funcional.

Palabras clave: Tecnología de asistencia; Lesiones de la médula espinal; Actividades diarias; Classificación internacional del funcionamiento, de la discapacidad y de la salud; Rehabilitacion fisica.

\section{Introdução}

Dados da World Health Organization [WHO] (2011) informa que no mundo 1 bilhão de pessoas vivem com algum tipo de deficiência. Para a WHO, a deficiência é: “complexa, dinâmica, multidimensional e questionada", que não pode ser analisada somente pelo modelo biomédico sem alinhar ao modelo social, em que traz em seu contexto o olhar para o deficiente além dos aspectos físicos (Brasil, 2015; World Health Organization, 2011).

As pessoas com lesão medular comumente têm limitações funcionais para o desempenho das atividades cotidianas, assim, o uso da tecnologia assistiva (TA) visa melhorar a funcionalidade da pessoa com deficiência. Em sua definição perpassa o conceito de produto, pois constitui uma área do conhecimento interdisciplinar, em que se agrega métodos, estratégias práticas e serviços alinhados com a atuação de profissionais e usuários. Ainda, em relação a sua confecção é possível ser realizada por qualquer pessoa. Portanto, não se limita a objetos de alto custo, mas também aqueles criados de modo artesanal. Todavia, a TA não é construída de acordo com a deficiência, mas segundo os parâmetros de funcionalidade (Angelina \& Soligo, 2016).

A expressão tecnologia assistiva foi criada em 1988 como elemento jurídico na legislação dos EUA denominado Public Law 100-407. No Brasil, o termo TA foi definido pelo CAT (Comitê de Ajudas Técnicas) em 2007, anteriormente era utilizado o termo "ajudas técnicas” descrito no decreto 5296/2004. Segundo o CAT, o termo tecnologia assistiva é considerado o mais adequado tanto na produção de documentos, como para a formação de recursos humanos, em pesquisas e nos referenciais teóricos. Assim, o CAT foi instituído pela portaria no 142 de 16 de novembro de 2006, sendo este um comitê criado pela Secretaria Especial dos Direitos Humanos da Presidência da República (SEDH/PR) em conjunto com a Coordenadoria Nacional para a Integração da Pessoa Portadora de Deficiência (Brasil, 2004; Rocha \& Castiglioni, 2005; Galvão Filho, 2009).

Nessa lógica, a TA não atende somente às pessoas com deficiência, mas a qualquer indivíduo que diante de algum comprometimento tenha necessidade de adquiri-la. Para tanto, a TA enquanto meio de inclusão social, permite que a pessoa com deficiência seja capaz de realizar ações e ou atividades antes limitadas por suas condições, como também contribui para que a mesma desenvolva as suas potencialidades e habilidades.

Ainda, no que concerne a TA é preciso compreendê-la como recurso para o usuário e não um recurso para o profissional, logo é de suma importância que se faça a diferenciação desta com outras tecnologias de aplicabilidade médica e de reabilitação que visam favorecer as atividades profissionais, sendo, portanto, consideradas recursos de trabalho (Bersch, 2017; Galvão Filho, 2009). 
A TA tende a contribuir para a promoção da autonomia e independência da pessoa com lesão medular, mas para isso, é necessário que esse recurso seja adequado e atenda às necessidades dos usuários. Também se deve estar atento a questão do abandono do dispositivo que pode ser devido ao estado físico do usuário; a falta de informação e treinamento tanto de profissionais quanto de usuários; dor; limitações funcionais [...] (Costa, Ferreira, Bortolus \& Carvalho, 2015).

Diante das inúmeras possibilidades e desafios que TA pode proporcionar para a pessoa com lesão medular, o presente estudo tem como objetivo: apresentar a aplicabilidade da TA para o desempenho das atividades cotidianas e para a promoção da autonomia funcional da pessoa com lesão medular.

\section{Metodologia}

Trata-se de uma revisão integrativa que tem como objetivo: "apresentar os achados de estudos desenvolvidos a partir de diferentes métodos, permitindo que os revisores procedam a análise e à síntese dos resultados de forma sistemática e rigorosa" (Soares et al., 2014, p. 336).

A revisão integrativa foi desenvolvida em cinco etapas. Na primeira etapa do método houve a elaboração da questão de pesquisa: Qual a aplicabilidade da Tecnologia Assistiva para o desempenho das atividades cotidianas e promoção da autonomia funcional em pessoas com lesão medular? A presente pergunta foi elaborada considerando que a TA é um recurso que visa contribuir para que pessoas com lesão medular tenham êxito no desempenho das atividades cotidianas, inclusive para o desenvolvimento de sua autonomia funcional. Contudo, caso esse recurso não corresponda as expectativas e necessidades dos indivíduos pode se tornar uma tecnologia dispensável.

Na segunda etapa foi definido os critérios de inclusão: publicações disponíveis em português, espanhol e inglês, publicados nos referidos bancos de dados, no período de 2015 a 2020. Após a busca nas bases de dados houve a elaboração do fluxograma com as etapas de seleção dos estudos com a identificação dos artigos duplicados, a leitura dos títulos e resumos com a remoção dos estudos não disponibilizados na íntegra e a inclusão daqueles que atenderam o objetivo da pesquisa. Foram excluídos do estudo artigos de revisão, fora do recorte temporal, incompletos e que não tinham relação com o objetivo do estudo.

Na revisão foram utilizadas as seguintes bases de dados: Literatura Latino-Americana e do Caribe em Ciências da Saúde (LILACS), IBECS e Bdenf através Biblioteca Virtual em Saúde (BVS), Scientific ElectronicLibrary Online (SciELO) e a National Library of Medicine (PubMed). A estratégia de busca foi realizada a partir dos descritores: (tecnologia assistiva) OR (equipamentos de autoajuda) OR (dispositivos assistivos) OR (dispositivos de autoajuda) OR (equipamentos assistivos) AND (autonomia pessoal) AND (Classificação Internacional de Funcionalidade, Incapacidade e Saúde) AND (traumatismos da medula espinhal) OR (lesões da medula espinhal) AND (atividades cotidianas) OR (atividades diárias).

$\mathrm{Na}$ terceira etapa foi extraído as informações chaves de cada artigo, dessa forma, foram selecionados os seguintes dados: ano de publicação, local, autoria, título, tipo de estudo, número de participantes, base de dados e periódico. O cálculo da frequência das palavras similares e o mapa conceitual foram processados a partir do Software Nvivo 12 Plus.

$\mathrm{Na}$ quarta etapa, os artigos foram selecionados para revisão integrativa através da verificação da autenticidade, qualidade metodológica, importância das informações (Quadro 1).

Na quinta etapa houve a interpretação e discussão dos resultados em consonância com o objetivo do estudo.

Segue, na Figura 1, a apresentação detalhada do fluxograma desenvolvido para o processo de seleção dos estudos identificados nas bases de dados da área de conhecimento, de acordo com o acima especificado. 
Figura 1. Fluxograma do processo de seleção dos estudos.

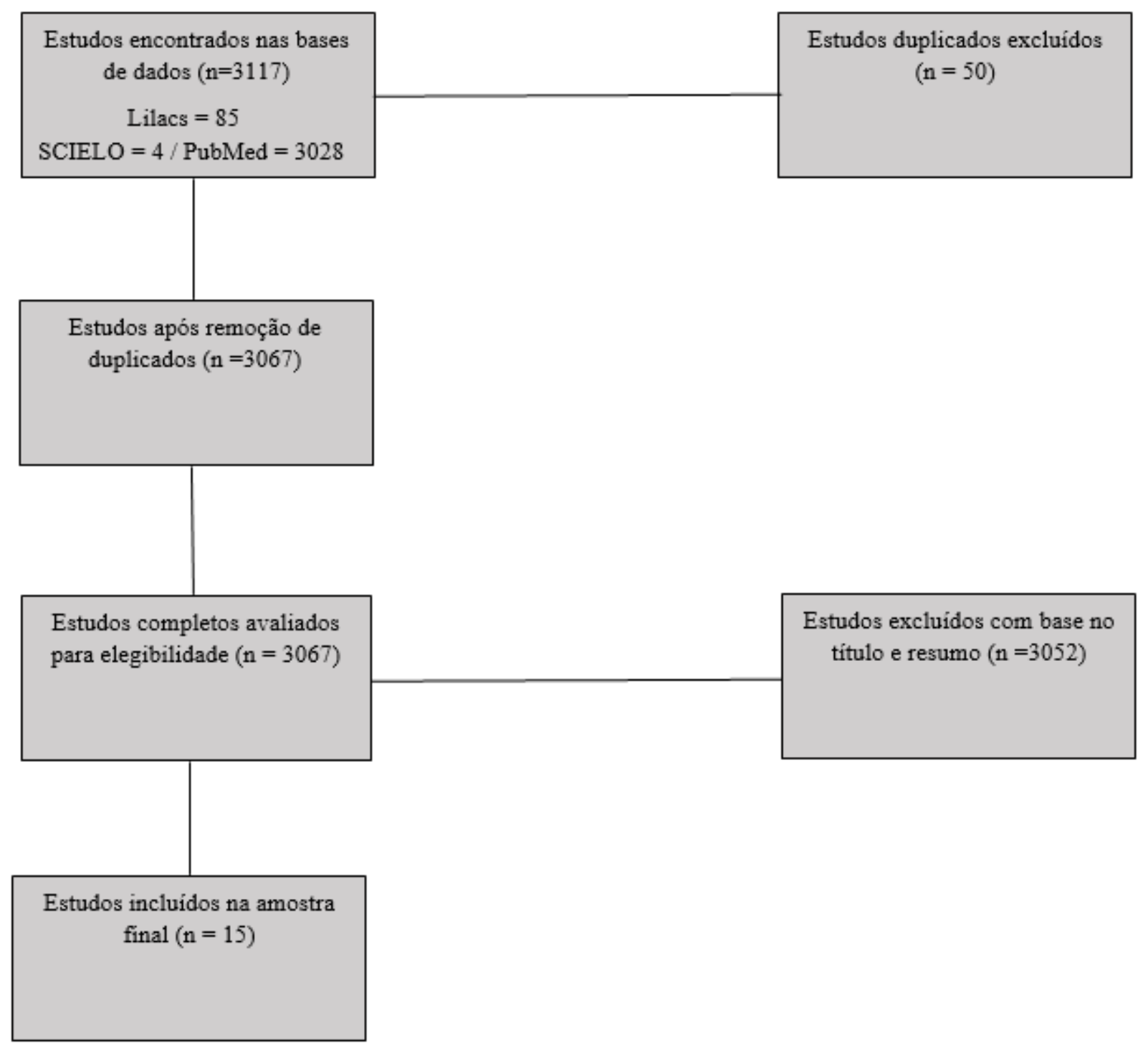

Fonte: Autores.

\section{Resultados}

A partir da caracterização dos estudos incluídos na revisão integrativa foi evidenciado o predomínio do método quantitativo, inclusive constatou-se que todos os artigos na revisão são internacionais (Quadro 1).

Com base nos artigos foram identificadas duas categorias: Tecnologia assistiva no desempenho das atividades cotidianas e Tecnologia assistiva na promoção da autonomia funcional (Quadro 2 e 3).

O Quadro 1 apresenta detalhamentos referentes ao ano de publicação, país, autoria, título, número de participantes, tipo de deficiência de todos os artigos incluídos na amostra, além da base de dados consultada e o periódico selecionado. 
Quadro 1. Caracterização dos artigos incluídos na amostra, Rio de Janeiro (RJ), Brasil, 2020.

\begin{tabular}{|c|c|c|c|c|}
\hline Ano/ Local & Autoria & Título & $\begin{array}{c}\text { Tipo de estudo / } \\
\text { no de participantes / } \\
\text { deficiência }\end{array}$ & $\begin{array}{c}\text { Base de } \\
\text { dados/Periódico }\end{array}$ \\
\hline $\begin{array}{l}2020 \\
\text { Turquia }\end{array}$ & $\begin{array}{l}\text { Degerli, Y. I et } \\
\text { al }\end{array}$ & $\begin{array}{l}\text { Fabricação de um dispositivo auxiliar } \\
\text { com impressão 3D tecnologia - um } \\
\text { relato de caso. }\end{array}$ & $\begin{array}{l}\text { Estudo de caso } \\
\mathrm{n}=1 \\
\text { Tetraplegia }\end{array}$ & $\begin{array}{l}\text { PubMed } \\
\text { Web of Science }\end{array}$ \\
\hline $\begin{array}{l}2020 \\
\text { Suécia }\end{array}$ & $\begin{array}{l}\text { Osuagwu, B. A. } \\
\text { C. et al }\end{array}$ & $\begin{array}{l}\text { A reabilitação domiciliar usando um } \\
\text { dispositivo de luva de mão robótica } \\
\text { leve leva à melhora na função da mão } \\
\text { em pessoas com lesão crônica da } \\
\text { medula espinhal: um estudo piloto. }\end{array}$ & $\begin{array}{l}\text { Ensaio clínico } \\
\mathrm{N}=15 \\
\text { Tetraplegia }\end{array}$ & $\begin{array}{l}\text { PubMed } \\
\text { J Neuroeng Rehabil }\end{array}$ \\
\hline $\begin{array}{l}2019 \\
\text { Espanha }\end{array}$ & $\begin{array}{l}\text { Bertomeu- } \\
\text { Motos, A. et al }\end{array}$ & $\begin{array}{l}\text { Sistema de reconhecimento de } \\
\text { atividade do usuário para melhorar o } \\
\text { desempenho de interfaces de controle } \\
\text { ambiental: um estudo piloto com } \\
\text { pacientes. }\end{array}$ & $\begin{array}{l}\text { Experimental } \\
\mathrm{N}=8 \\
\text { Tetraplegia /outras doenças } \\
\text { neurológicas }\end{array}$ & $\begin{array}{l}\text { PubMed } \\
\text { J Neuroeng Rehabil }\end{array}$ \\
\hline $\begin{array}{l}2019 \\
\text { Alemanha }\end{array}$ & $\begin{array}{l}\text { Goudal, F. F. et } \\
\text { al }\end{array}$ & $\begin{array}{l}\text { Assistente robótico autônomo } \\
\text { multissensorial para uma tarefa de } \\
\text { beber. }\end{array}$ & $\begin{array}{l}\text { Experimental } \\
\mathrm{n}=16 \\
* 1 \quad \text { participante com } \\
\text { Tetraplegia }\end{array}$ & $\begin{array}{l}\text { PubMed } \\
\text { IEEE International } \\
\text { Conference on } \\
\text { Rehabilitation Robotics }\end{array}$ \\
\hline Coréia & Yoo, H. J. et al & $\begin{array}{l}\text { Desenvolvimento de órteses } \\
\text { mioelétricas de mão impressas em 3D } \\
\text { para pacientes com lesão da medula } \\
\text { espinhal. }\end{array}$ & $\begin{array}{l}\text { Experimental } \\
\mathrm{n}=10 \\
\text { Tetraplegia }\end{array}$ & $\begin{array}{l}\text { PubMed } \\
\text { Journal } \\
\text { NeuroEngineering and } \\
\text { Rehabilitation }\end{array}$ \\
\hline $\begin{array}{l}2018 \\
\text { EUA }\end{array}$ & Capello, L. et al & $\begin{array}{l}\text { Auxiliar a função da mão após lesão } \\
\text { da medula espinhal com uma luva } \\
\text { robótica macia de tecido. }\end{array}$ & $\begin{array}{l}\text { Estudo de caso } \\
\mathrm{n}=9 \\
\text { Tetraplegia }\end{array}$ & $\begin{array}{l}\text { PubMed Journal of } \\
\text { NeuroEngineering and } \\
\text { Rehabilitation }\end{array}$ \\
\hline $\begin{array}{l}2018 \\
\text { EUA }\end{array}$ & Etingen, B. et al & $\begin{array}{l}\text { Percepções do paciente sobre unidades } \\
\text { de controle ambiental: experiências de } \\
\text { veteranos com lesões e distúrbios da } \\
\text { medula espinhal internados no VA } \\
\text { recebendo cuidados de saúde. } \\
\text { *Department of Veterans Affairs (VA) }\end{array}$ & $\begin{array}{l}\text { Quantitativo/Descritivo } \\
\mathrm{n}=70 \\
\text { Lesão/doença medular }\end{array}$ & $\begin{array}{l}\text { PubMed } \\
\text { Disability and } \\
\text { Rehabilitation: } \\
\text { Assistive Technology }\end{array}$ \\
\hline $\begin{array}{l}2018 \\
\text { Austrália }\end{array}$ & Hooper, B. et al & $\begin{array}{l}\text { Sistemas de controle ambiental com } \\
\text { dispositivos inteligentes: experiências } \\
\text { de pessoas com lesão medular } \\
\text { cervical. }\end{array}$ & $\begin{array}{l}\text { Fenomenológico } \\
\mathrm{n}=5 \\
\text { Tetraplegia }\end{array}$ & $\begin{array}{l}\text { PubMed } \\
\text { Disability and } \\
\text { Rehabilitation: } \\
\text { Assistive Technology }\end{array}$ \\
\hline $\begin{array}{l}2018 \\
\text { Coréia }\end{array}$ & $\begin{array}{l}\text { Yeo, S. S \& } \\
\text { Kwon, J. W }\end{array}$ & $\begin{array}{l}\text { Treinamento de habilidades para } \\
\text { cadeira de rodas para atividades } \\
\text { funcionais em adultos com lesão da } \\
\text { medula espinhal cervical. }\end{array}$ & $\begin{array}{l}\text { Ensaio clínico } \\
\mathrm{N}=26 \\
\text { Tetraplegia }\end{array}$ & $\begin{array}{l}\text { PubMed } \\
\text { Int J Sports Med }\end{array}$ \\
\hline
\end{tabular}


Research, Society and Development, v. 10, n. 8, e0210815387, 2021

(CC BY 4.0) | ISSN 2525-3409 | DOI: http://dx.doi.org/10.33448/rsd-v10i8.15387

\begin{tabular}{|c|c|c|c|c|}
\hline $\begin{array}{l}2017 \\
\text { Espanha }\end{array}$ & Rashid, Z. et al & $\begin{array}{l}\text { Uma experiência } \text { de compra } \\
\text { independente para } \\
\text { cadeiras de rodas por meirios de } \\
\text { realidade e RFID. }\end{array}$ & $\begin{array}{l}\text { Experimental } \\
\mathrm{N}=18 \\
\text { Mobilidade reduzida } \\
\begin{array}{l}\text { Dificuldade } \\
\text { comunicação }\end{array}\end{array}$ & $\begin{array}{l}\text { PubMed } \\
\text { Assistive Technology }\end{array}$ \\
\hline $\begin{array}{l}2017 \\
\text { Coréia }\end{array}$ & Kim, B. et al & $\begin{array}{l}\text { Desenvolvimento e avaliação de um } \\
\text { dispositivo de assistência manual: } \\
\text { GRIPIT. }\end{array}$ & $\begin{array}{l}\text { Misto } \\
\mathrm{n}=4 \\
\text { Tetraplegia }\end{array}$ & $\begin{array}{l}\text { PubMed } \\
\text { Journal } \\
\text { NeuroEngineering and } \\
\text { Rehabilitation }\end{array}$ \\
\hline $\begin{array}{l}2016 \\
\text { Tânzania }\end{array}$ & $\begin{array}{l}\text { Seyi, A.; Aston, } \\
\text { N.; Helen, B }\end{array}$ & $\begin{array}{l}\text { Cadeiras de rodas fabricadas } \\
\text { localmente na Tanzânia - os usuários } \\
\text { estão satisfeitos? }\end{array}$ & $\begin{array}{l}\text { Transversal descritivo } \\
\mathrm{N}=75 \\
\text { lesão medular }\end{array}$ & $\begin{array}{l}\text { PubMed } \\
\text { Afr Health Sci }\end{array}$ \\
\hline $\begin{array}{l}2015 \\
\text { Austrália }\end{array}$ & $\begin{array}{l}\text { Friesen, E. L.; } \\
\text { Theodoros, D.; } \\
\text { Russell, T. G. }\end{array}$ & $\begin{array}{l}\text { Uso, desempenho e recursos de } \\
\text { chuveiros móveis: perspectivas de } \\
\text { adultos com lesão medular e médicos } \\
\text { especialistas. }\end{array}$ & $\begin{array}{l}\text { Qualitativa } \\
\mathrm{N}=8 \\
\text { Tetraplegia } \\
\text { Paraplegia }\end{array}$ & $\begin{array}{l}\text { PubMed } \\
\text { Disabil Rehabil Assist } \\
\text { Technol }\end{array}$ \\
\hline $\begin{array}{l}2015 \\
\text { Austrália }\end{array}$ & $\begin{array}{lr}\text { Folan, } & \text { A.; } \\
\text { Barclay, } & \text { L.; } \\
\text { Cooper } & \text { C.; } \\
\text { Robinson, } & \text { M. }\end{array}$ & $\begin{array}{l}\text { Explorando a experiência de clientes } \\
\text { com tetraplegia utilizando tecnologia } \\
\text { assistiva para acesso ao computador. }\end{array}$ & $\begin{array}{l}\text { Qualitativa } \\
\mathrm{N}=7 \\
\text { tetrapelgia }\end{array}$ & $\begin{array}{l}\text { PubMed } \\
\text { Disabil Rehabil Assist } \\
\text { Technol }\end{array}$ \\
\hline $\begin{array}{l}2015 \\
\text { EUA }\end{array}$ & Khalid, U. et al & $\begin{array}{l}\text { Pegador de objetos leve ativado por } \\
\text { voz para auxiliar nas limitações de } \\
\text { movimento da extremidade superior: } \\
\text { um estudo de caso. }\end{array}$ & $\begin{array}{l}\text { Experimental } \\
\mathrm{N}=1 \\
\mathrm{~N}=6 \\
\text { Tetraplegia }\end{array}$ & $\begin{array}{l}\text { PubMed } \\
\text { Assistive Technology }\end{array}$ \\
\hline
\end{tabular}

Fonte: Elaborado pelos autores do estudo (2020).

A Tabela 1 apresenta o percentual ponderado de palavras similares, assim observou-se que os termos participantes, cadeiras de rodas, tecnologia, reabilitação e avaliação obtiveram o maior número de citações. O termo cadeira de rodas enquanto TA foi o segundo termo mais destacado com um percentual de $0,45 \%$. 
Tabela 1. Percentual ponderado de palavras similares extraídas dos artigos, Rio de Janeiro (RJ), Brasil, 2020.

\begin{tabular}{|c|c|c|c|c|}
\hline Palavras & Extensão & Contagem & $\begin{array}{c}\text { Percentual } \\
\text { ponderado }(\%)\end{array}$ & Palavras similares \\
\hline participantes & 12 & 800 & 1,06 & $\begin{array}{c}\text { ativação, ativação, atividades, engajamento, } \\
\text { envolvimento, participante, participantes, } \\
\text { participantes, participar, participar, participar, } \\
\text { participação }\end{array}$ \\
\hline cadeira de rodas & 10 & 312 & 0,45 & cadeira de rodas, cadeiras de rodas \\
\hline tecnologia & 10 & 309 & 0,42 & $\begin{array}{c}\text { engenharia, tecnologia, tecnologias, tecnologia, } \\
\text { tecnologia }\end{array}$ \\
\hline reabilitação & 14 & 286 & 0,41 & $\begin{array}{c}\text { reconstruindo, reconstrutivo, reabilitado, reabilitação, } \\
\text { reabilitador }\end{array}$ \\
\hline avaliação & 10 & 253 & 0,33 & $\begin{array}{c}\text { avaliação, avaliações, avaliação, avaliação, avaliações, } \\
\text { medição, medições }\end{array}$ \\
\hline experiência & 10 & 237 & 0,32 & $\begin{array}{l}\text { experiência, experiente, experiências, vivência, } \\
\text { experimento, experimental, experimentalmente, } \\
\text { experimentação, experimentação, experimentos }\end{array}$ \\
\hline Individual & 11 & 160 & 0,19 & $\begin{array}{l}\text { individual, individualizado, individualizando, } \\
\text { individualizado, individualmente, indivíduos, } \\
\text { indivíduos, personalizado, personalidade, } \\
\text { personalizado, separadamente }\end{array}$ \\
\hline desempenho & 10 & 123 & 0,18 & $\begin{array}{l}\text { funcional, funcionalidades, funcionalidade, } \\
\text { funcionalmente, funcionamento, operações, } \\
\text { desempenho, desempenhos, desempenho }\end{array}$ \\
\hline Independência & 12 & 143 & 0,16 & $\begin{array}{l}\text { autônomo, autônomo, independência, independência, } \\
\text { independente, independente }\end{array}$ \\
\hline significativo & 11 & 107 & 0,14 & $\begin{array}{l}\text { implicação, implicações, importância, mais } \\
\text { importante, significância, significativo, significativo, } \\
\text { substancial, substancialmente }\end{array}$ \\
\hline melhoria & 11 & 93 & 0,13 & $\begin{array}{l}\text { adicional, além disso, avanços, melhoria, melhoria, } \\
\text { melhorias }\end{array}$ \\
\hline universidade & 10 & 85 & 0,12 & $\begin{array}{l}\text { generalizações, generalizar, generalizar, população, } \\
\text { populações, universidade }\end{array}$ \\
\hline incapacidade & 10 & 73 & 0,10 & $\begin{array}{l}\text { deficiência, deficiência, deficiente, deficiência, } \\
\text { deficiências, incapacitante }\end{array}$ \\
\hline manipulação & 11 & 78 & 0,10 & $\begin{array}{c}\text { controlabilidade, controlado, controlador, } \\
\text { controladores, controle, manipular, manipular, } \\
\text { manipular, manipulação, manipulações, manipulador, } \\
\text { manipuladores, operações, utilidade }\end{array}$ \\
\hline
\end{tabular}

Fonte: Elaborado pelos autores do estudo (2020) a partir do Software Nvivo 12 Plus, 2020.

O Quadro 2 apresenta detalhamentos da primeira categoria, denominada: "Tecnologia assistiva no desempenho das atividades cotidianas”, demonstrando a relação entre o título, os objetivos e os dados evidenciados nos estudos analisados. 
Quadro 2. Tecnologia assistiva no desempenho das atividades cotidianas.

\begin{tabular}{|c|c|c|}
\hline Título & Objetivos & Dados Evidenciados \\
\hline $\begin{array}{l}\text { A reabilitação domiciliar } \\
\text { usando um dispositivo de } \\
\text { luva de mão robótica leve } \\
\text { leva à melhora na função } \\
\text { da mão em pessoas com } \\
\text { lesão crônica da medula } \\
\text { espinhal: um estudo piloto }\end{array}$ & $\begin{array}{l}\text { Investigar o efeito terapêutico de um programa } \\
\text { de reabilitação de mãos autoadministrado em } \\
\text { casa para pessoas com LM cervical usando a } \\
\text { soft extra muscle (SEM) Glove da Bioservo } \\
\text { Technologies AB. }\end{array}$ & $\begin{array}{l}\text { O TRI-HFT demonstrou melhora na função da mão na } \\
\text { semana } 6 \text { da terapia, incluindo melhora na manipulação } \\
\text { de objetos }(58,3 \pm 3,2 \text { a } 66,9 \pm 1,8, \mathrm{p} \approx 0,01) \text {, e } \\
\text { preensão palmar avaliada como o comprimento da } \\
\text { barra de madeira que pode ser realizada com preensão } \\
\text { palmar pronada }(29,1 \pm 6,0 \mathrm{~cm} \text { a } 45,8 \pm 6,8 \mathrm{~cm}, \mathrm{p} \\
<0,01) \text {. Uma melhora significativa na força de pinça, } \\
\text { com redução da hipertonia do músculo polegar também } \\
\text { foi detectada. As melhorias na função estiveram } \\
\text { presentes durante a avaliação da semana } 12 \text { e também } \\
\text { durante o acompanhamento. }\end{array}$ \\
\hline $\begin{array}{l}\text { Desenvolvimento } \text { de } \\
\text { órteses mioelétricas de } \\
\text { mão impressas em 3D para } \\
\text { pacientes com lesão da } \\
\text { medula espinhal }\end{array}$ & $\begin{array}{l}\text { Demonstrar os efeitos da órtese mioelétrica de } \\
\text { mão impressa em 3D } \\
\text { em pacientes com lesão medular cervical. }\end{array}$ & $\begin{array}{l}\text { A órtese mioelétrica de mão impressa em 3D foi } \\
\text { intuitiva, fácil de usar e mostrou efeitos positivos em } \\
\text { sua capacidade de manusear objetos encontrados na } \\
\text { vida diária. Este estudo provou que a combinação de } \\
\text { estratégias simples de controle baseadas em EMG e } \\
\text { técnicas de impressão 3D era viável e promissora na } \\
\text { engenharia de reabilitação. }\end{array}$ \\
\hline $\begin{array}{l}\text { Assistente } r \text { robótico } \\
\text { autônomo multissensorial } \\
\text { para uma tarefa de beber }\end{array}$ & $\begin{array}{l}\text { Apresentar uma solução robótica como } \\
\text { tentativa de capacitar uma pessoa com } \\
\text { tetraplegia a tarefa de beber de modo } \\
\text { independente sem ajuda humana externa e sem } \\
\text { quaisquer elementos fixados ao usuário. }\end{array}$ & $\begin{array}{l}\text { A solução proposta funciona como uma solução } \\
\text { amigável e segura de controle para uma tarefa de beber. } \\
\text { Os experimentos mostraram uma alta confiabilidade e } \\
\text { aceitação do usuário. }\end{array}$ \\
\hline $\begin{array}{l}\text { Auxiliar a função da mão } \\
\text { após lesão da medula } \\
\text { espinhal com uma luva } \\
\text { robótica macia de tecido. }\end{array}$ & $\begin{array}{l}\text { Demonstrar que uma robotic glove macia à } \\
\text { base de tecido pode ajudar efetivamente os } \\
\text { participantes afetados por lesão na medula } \\
\text { espinhal na manipulação de objetos } \\
\text { encontrados na vida diária. }\end{array}$ & $\begin{array}{l}\text { Os resultados obtidos neste estudo validam que a luva } \\
\text { robótica macia feita de tecido como um dispositivo } \\
\text { eficaz para auxiliar a função da mão em indivíduos que } \\
\text { sofreram paralisia do membro superior após uma lesão } \\
\text { na medula espinhal. }\end{array}$ \\
\hline $\begin{array}{l}\text { Treinamento de } \\
\text { habilidades para cadeira de } \\
\text { rodas para atividades } \\
\text { funcionais em adultos com } \\
\text { lesão da medula espinhal } \\
\text { cervical. }\end{array}$ & $\begin{array}{l}\text { Examinar a eficácia do treinamento de } \\
\text { habilidades em cadeira de rodas para melhorar } \\
\text { as habilidades em cadeira de rodas e o } \\
\text { desempenho de habilidades do braço em } \\
\text { adultos com C-SCI. } \\
\text { *C-SCI (lesão da medula espinhal cervical) }\end{array}$ & $\begin{array}{l}\text { Todos os indivíduos foram testados com o Wheelchair } \\
\text { Skills Test (WST) e o Van Lieshout Test (VLT). O } \\
\text { teste foi repetido no pré e pós-treinamento (após } 4 \\
\text { semanas e } 8 \text { semanas). Para WST, a análise univariada } \\
\text { demonstrou efeitos principais significativos na } \\
\text { interação entre grupos, dentro do grupo e grupo por } \\
\text { tempo (p <0,05). O VLT não apresentou efeito } \\
\text { significativo na comparação entre os grupos ( }>0,05 \text { ), } \\
\text { enquanto a comparação dentro do grupo dos tempos de } \\
\text { teste e a interação grupo a tempo mostraram efeitos } \\
\text { principais significativos (p <0,05). Assim, o } \\
\text { treinamento de habilidades em cadeira de rodas é mais } \\
\text { benéfico para adultos com C-SCI do que o exercício } \\
\text { convencional. }\end{array}$ \\
\hline $\begin{array}{l}\text { Desenvolvimento } \text { e } \\
\text { avaliação de um } \\
\text { dispositivo de assistência } \\
\text { manual: GRIPIT }\end{array}$ & $\begin{array}{l}\text { Ajudar os usuários a agarrar as ferramentas } \\
\text { com as próprias mãos, usando um dispositivo } \\
\text { auxiliar leve e compacto (GRIPIT) que é } \\
\text { operado manualmente por meio de um único } \\
\text { fio. }\end{array}$ & $\begin{array}{l}\text { GRIPIT tem um alto potencial para aumentar a } \\
\text { qualidade de vida das pessoas com paralisia das mãos, } \\
\text { pois pode ajudar os usuários a agarrar uma variedade de } \\
\text { ferramentas, enquanto os dispositivos convencionais } \\
\text { podem aceitar apenas produtos que encaixam no } \\
\text { orifício. }\end{array}$ \\
\hline $\begin{array}{l}\text { Cadeiras de rodas } \\
\text { fabricadas localmente na } \\
\text { Tanzânia - os usuários } \\
\text { estão satisfeitos? }\end{array}$ & $\begin{array}{l}\text { Avaliar até que ponto as cadeiras de rodas } \\
\text { atendiam às necessidades de atividade e } \\
\text { participação dos usuários, bem como o nível de } \\
\text { satisfação dos usuários com o fornecimento, } \\
\text { reparo e manutenção dessas cadeiras de rodas. }\end{array}$ & $\begin{array}{l}\text { Os participantes usaram cadeira de rodas por um } \\
\text { período médio de } 9,3 \text { anos. A maioria dos participantes } \\
(61 \%) \text { sofreram lesões na medula espinhal e usavam } \\
\text { cadeiras de três rodas }(76 \%) \text {. Mais de } 90 \% \text { relataram } \\
\text { que suas cadeiras de rodas influenciaram positivamente } \\
\text { suas necessidades de atividade e participação, e } 85 \% \\
\text { estavam satisfeitos com sua capacidade de realizar as } \\
\text { atividades diárias. Os participantes expressaram } \\
\text { satisfação com a durabilidade das cadeiras de rodas } \\
(89 \%) \text { e os serviços profissionais recebidos ( } 71 \%) \text {, mas } \\
\text { não com os serviços de acompanhamento } \\
(77 \%) \text {. Houve diferença na satisfação com as } \\
\text { características das cadeiras rígidas de } 3 \text { e } 4 \text { rodas (p }= \\
0,030) \text {. }\end{array}$ \\
\hline
\end{tabular}




\begin{tabular}{|l|l|l|}
\hline $\begin{array}{l}\text { Pegador de objetos leve } \\
\text { ativado por voz para } \\
\text { auxiliar nas limitações de } \\
\text { movimento da extremidade } \\
\text { superior: um estudo de } \\
\text { caso }\end{array}$ & $\begin{array}{l}\text { Projetar um alcance funcional e fácil de usar } \\
\text { para pessoas com lesões da medula espinhal } \\
\text { (SCI). }\end{array}$ & $\begin{array}{l}\text { Para o experimento de mesa, o indivíduo SCI } \\
\text { completou com sucesso as tarefas seguindo as } \\
\text { instruções fornecidas. Ele foi capaz de colocar o objeto } \\
\text { com precisão nos locais especificados. Para ambos os } \\
\text { experimentos de mesa, o indivíduo SCI realizou as } \\
\text { tarefas com sucesso }\end{array}$ \\
$\begin{array}{l}\text { Uso, desempenho e e } \\
\text { recursos de chuveiros } \\
\text { móveis: perspectivas de } \\
\text { adultos com lesão medular } \\
\text { e médicos especialistas. }\end{array}$ & $\begin{array}{l}\text { Explorar o uso de Mobile Shower Commodes } \\
\text { espinhal por adultos com lesão da medula e compreender como adultos } \\
\text { com SCI e médicos especialistas identificam e } \\
\text { selecionam designs e recursos de MSC. }\end{array}$ & $\begin{array}{l}\text { A análise das transcrições das entrevistas revelou 3 } \\
\text { atividades, rotinas, fatores de interação, recursos para o } \\
\text { funcionamento e para fazer da maneira certa. Links } \\
\text { substanciais existiam entre os temas e subtemas. }\end{array}$ \\
\hline
\end{tabular}

Fonte: Elaborado pelos autores do estudo (2020).

O Quadro 3 apresenta detalhamentos da segunda categoria, denominada: "Tecnologia assistiva na promoção da autonomia funcional", da mesma forma, demonstrando a relação entre o título, os objetivos e os dados evidenciados nos estudos analisados.

Quadro 3. Tecnologia assistiva na promoção da autonomia funcional.

\begin{tabular}{|c|c|c|}
\hline Título & Objetivos & Dados Evidenciados \\
\hline $\begin{array}{l}\text { Fabricação de um dispositivo } \\
\text { auxiliar com impressão 3D } \\
\text { tecnologia - um relato de caso }\end{array}$ & $\begin{array}{l}\text { Definir o projeto e o procedimento de } \\
\text { um dispositivo auxiliar impresso em } \\
\text { 3D e produzir um protótipo dispositivo } \\
\text { auxiliar para um indivíduo com } \\
\text { tetraplegia, a fim de permitir que ele / } \\
\text { ela conduza de forma independente as } \\
\text { atividades da vida diária. }\end{array}$ & $\begin{array}{l}\text { O dispositivo de assistência teve um efeito } \\
\text { significativo na independência do indivíduo, já que o } \\
\text { mesmo pode escrever e assinar o seu nome sem } \\
\text { tremores de forma independente. }\end{array}$ \\
\hline $\begin{array}{l}\text { Sistema de reconhecimento de } \\
\text { atividade do usuário para } \\
\text { melhorar o desempenho de } \\
\text { interfaces de controle ambiental: } \\
\text { um estudo piloto com pacientes }\end{array}$ & $\begin{array}{l}\text { Avaliar a interface de controle de } \\
\text { ambiente (ICE) desenvolvida nas } \\
\text { condições do projeto AIDE, uma } \\
\text { interface multimodal capaz de analisar } \\
\text { e extrair informações Relevantes dos } \\
\text { ambientes, bem como a partir da } \\
\text { identificação de habilidades residuais, } \\
\text { comportamentos e intenções do } \\
\text { usuário. }\end{array}$ & $\begin{array}{l}\text { Os resultados mostram que o tempo médio da tarefa } \\
\text { gasto no modo AIDE foi menor do que no Manual, } \\
\text { ou seja, os usuários conseguiram realizar mais tarefas } \\
\text { no modo AIDE durante o mesmo tempo. Os } \\
\text { resultados mostraram diferenças estatisticamente } \\
\text { significativas com p <0,001. Em relação às etapas, ou } \\
\text { seja, o número de níveis de abstração cruzados no } \\
\text { ECI para realizar uma AVD, os usuários realizaram } \\
\text { uma etapa em 90\% das tarefas utilizando o modo } \\
\text { AIDE e três etapas, pelo menos, foram necessárias no } \\
\text { modo Manual. A previsão da intenção do usuário foi } \\
\text { realizada por meio de campos aleatórios condicionais } \\
\text { (CRF), com uma acurácia global em torno de } 87 \% \text {. }\end{array}$ \\
\hline $\begin{array}{l}\text { Percepções do paciente sobre } \\
\text { unidades de controle ambiental: } \\
\text { experiências de veteranos com } \\
\text { lesões e distúrbios da medula } \\
\text { espinhal internados no VA } \\
\text { recebendo cuidados de saúde. } \\
\text { *Department of Veterans Affairs } \\
\text { (VA) }\end{array}$ & $\begin{array}{l}\text { Avaliar as percepções dos pacientes } \\
\text { sobre unidades de controle ambiental } \\
\text { (ECUs) no Veterans Affairs Spinal } \\
\text { Cord Injury Centers. }\end{array}$ & $\begin{array}{l}\text { Os recursos ECU usados mais frequentemente para } \\
\text { assistir TV / filmes, ligar a enfermaria (acendendo e } \\
\text { apagando as luzes) e ajustar a cama. Muitos } \\
\text { entrevistados no local sentiram que a ECU atendia às } \\
\text { suas necessidades de independência. A maioria dos } \\
\text { entrevistados em ambas as pesquisas estavam } \\
\text { satisfeitos com a ECU. }\end{array}$ \\
\hline $\begin{array}{l}\text { Sistemas de controle ambiental } \\
\text { com dispositivos inteligentes: } \\
\text { experiências de pessoas com } \\
\text { lesão medular cervical. }\end{array}$ & $\begin{array}{l}\text { Abordar as experiências dos usuários } \\
\text { com o dispositivo inteligente ECS, no } \\
\text { estado australiano de Queensland. }\end{array}$ & $\begin{array}{l}\text { A experiência de usar um dispositivo inteligente ECS } \\
\text { apresentou oportunidades e custos para os usuários. } \\
\text { As oportunidades incluíram: controle independente, } \\
\text { escolha, tranquilidade, conexão, uso eficaz de } \\
\text { recursos e controle sobre funções e aplicativos de } \\
\text { smartphones. Os custos associados incluem: } \\
\text { limitações financeiras, de tempo, frustração e } \\
\text { técnicas. }\end{array}$ \\
\hline
\end{tabular}




\begin{tabular}{|c|c|c|}
\hline $\begin{array}{l}\text { Uma experiência de compra } \\
\text { independente para usuários de } \\
\text { cadeiras de rodas por meio de } \\
\text { realidade e RFID }\end{array}$ & $\begin{array}{l}\text { Projetar, desenvolver e avaliar } \\
\text { soluções de acesso a produtos distantes } \\
\text { do alcance do cadeirante sem depender } \\
\text { da ajuda de terceiros. }\end{array}$ & $\begin{array}{l}\text { O estudo forneceu soluções práticas que ajustam as } \\
\text { necessidades dos deficientes a partir de espaços } \\
\text { inteligentes habilitados para o RFID, AR em } \\
\text { smartphones, ou tablets e telas sensíveis ao toque. Os } \\
\text { resultados foram promissores para a promoção, } \\
\text { independência e autonomia dos cadeirantes nas } \\
\text { atividades de compras. }\end{array}$ \\
\hline $\begin{array}{l}\text { Explorando a experiência de } \\
\text { clientes com tetraplegia } \\
\text { utilizando } \\
\text { Tecnologia assistiva para acesso } \\
\text { ao computador }\end{array}$ & $\begin{array}{l}\text { Obter uma compreensão de } \\
\text { experiências de clientes com } \\
\text { tetraplegia experimentando tecnologia } \\
\text { assistiva para acesso a computador em } \\
\text { diferentes etapas de um serviço } \\
\text { público de reabilitação. }\end{array}$ & $\begin{array}{l}\text { Os resultados deste estudo demonstraram que pessoas } \\
\text { com tetraplegia podem ser auxiliadas a retornar aos } \\
\text { papéis da vida anterior ou se engajar em novos } \\
\text { papéis, através do desenvolvimento de habilidades no } \\
\text { uso de tecnologia assistiva para acesso a } \\
\text { computadores. Ser capaz de usar computadores para } \\
\text { atividades significativas contribuiu para que os } \\
\text { participantes ganhassem um melhor senso de } \\
\text { autoeficácia e, portanto, qualidade de vida. }\end{array}$ \\
\hline
\end{tabular}

Fonte: Elaborado pelos autores do estudo (2020).

A Figura 2 específica que a maioria dos estudos apresentaram dispositivos auxiliares capazes de melhorar o desempenho de pessoas com lesão medular e com comprometimento de membros superiores, destacando que a TA viabilizou o desempenho das atividades cotidianas, como demonstrado a seguir:

Figura 2. Mapa conceitual da Tecnologia Assistiva com as respectivas habilidades e tarefas.

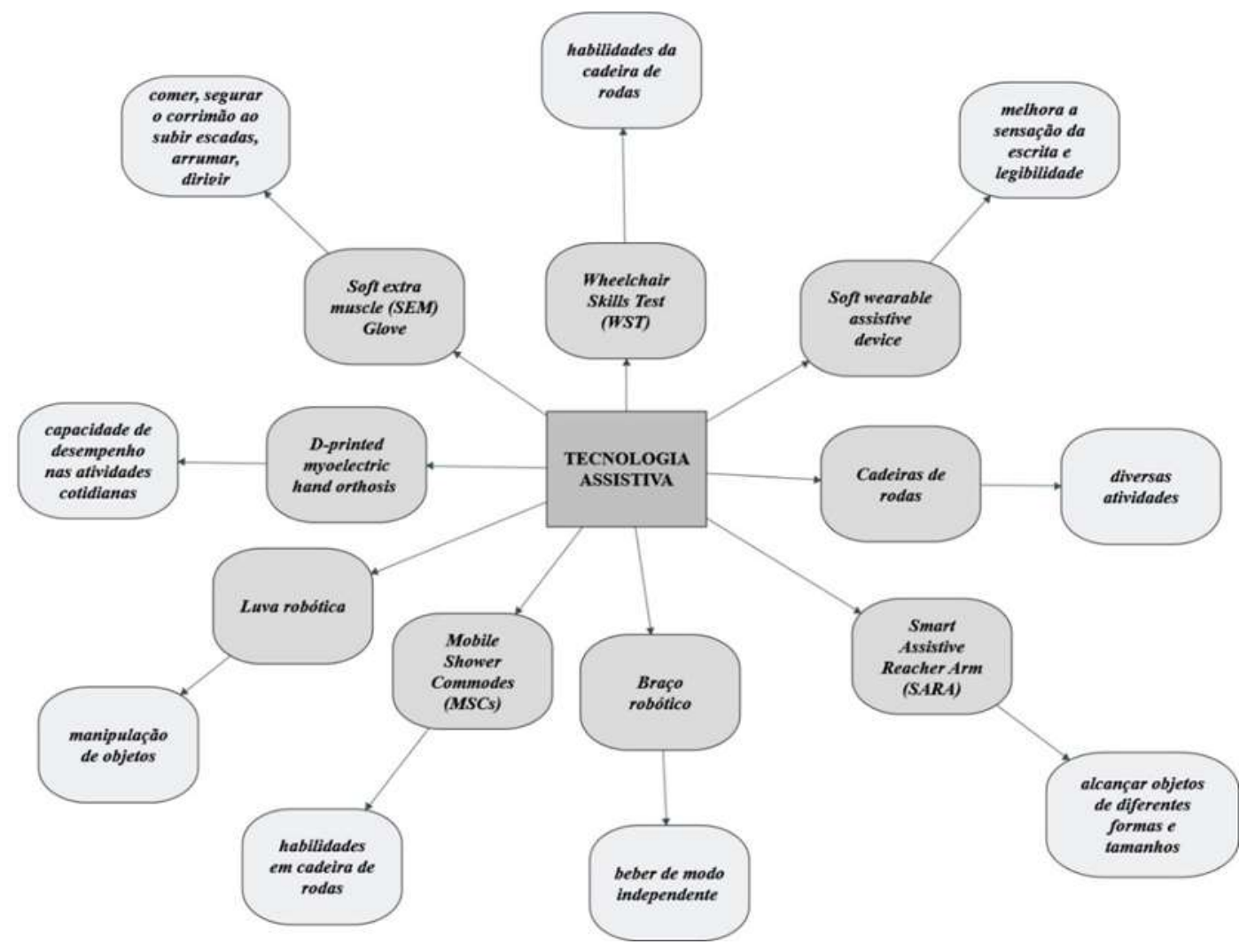

Fonte: Elaborado pelos autores do estudo a partir do Software Nvivo 12 Plus (2020).

\section{Discussão}

Ao analisar a funcionalidade da tecnologia assistiva, as evidências científicas constataram que esses recursos tecnológicos podem favorecer a pessoa com lesão medular em suas atividades cotidianas, mas também pode ser uma 
tecnologia desafiadora para o desempenho de suas habilidades. Um estudo que buscou investigar os efeitos terapêuticos de um soft extra muscle (SEM) Glove da Bioservo Technologies AB, evidenciou que o dispositivo melhora as funções das mãos em pessoas com lesão meduar espinhal. Através do teste de função manual do Toronto Rehabilitation Institute Hand Function Test (TRI-HFT) foi possível medir a função motora grossa da mão durante o estudo. Assim, durante o estudo a maioria dos participantes afirmaram que através dispositivo auxiliar foi possível realizar várias atividades como: comer, segurar o corrimão ao subir escadas, arrumar, dirigir e também para a realização de outras tarefas bimanuais. Também foi observado pelos participantes que a luva melhora a preensão e força de preensão que são componentes importantes para a manipulação de objetos durante as atividades cotidianas (Osuagwu et al., 2020).

Do mesmo modo, o estudo desenvolvido por Yoo, Lee, Kim, Park e Lee (2019) que objetivou demostrar os efeitos da 3D-printed myoelectric hand orthosis em pacientes com lesão medular apresentou resultados satisfatórios quanto a capacidade de desempenho nas atividades cotidianas. O experimento foi projetado para comparar as situações com e sem a órtese. Assim, antes de colocar a órtese os participantes foram submetidos a avaliações quanto as funções da mão e em relação a independência funcional na vida diária. A função da mão do lado dominante foi avaliada usando o teste de função manual do Toronto Rehabilitation Institute Hand Function Test (TRI-HFT). O teste propõe avaliar a função motora grossa unilateral de pacientes com lesão medular (C4 - C7) usando objetos padronizados que podem ser encontrados na vida diária. A independência funcional foi avaliada usando a Functional Independence Measure (FIM) e a Spinal Cord Independence Measure (SCIM) III.

Similarmente, houve na avaliação quanto a satisfação do usuário através do Korean-Quebec User Evaluation of Satisfaction with Assistive Technology 2.0 (K-QUEST 2.0). Os itens segurança, simplicidade de uso, conforto e eficácia do dispositivo receberam pontuações altas dos participantes. Entretanto, nos itens dimensões e ajustes as pontuações foram baixas. Apesar das limitações, a maioria dos participantes, relataram que o uso da órtese mioelétrica melhorou significativamente a função da mão, inclusive o dispositivo obteve feedback positivo no teste de usabilidade (Yoo et al., 2019).

Nesse sentido, as órteses de apoio funcional para mãos têm sido importantes instrumentos pra auxiliar na reabilitação em indivíduos com lesão medular alta, isso porque têm o potencial de auxiliar sem proporcionar grandes custos ou cirurgias. No caso, de clientes que apresentam comprometimento funcionais crônicos em mão e punho, como nos casos de lesão de plexo braquial, lesões medulares e doenças neurológicas e degenerativas, as órteses têm se mostrado um grande desafio (Meneses, Rocha, Corrêa \& Pinotti, 2008).

Meneses, Rocha, Júnior, Sono, Oliveira e Pinotti (2012) em seus estudos objetivaram descrever os primeiros testes de um protótipo de órtese funcional para mão, definida como luva funcional, em indivíduos adultos com paralisia em mão e punho, devido a lesão do plexo braquial. Para tanto, constatou-se que os participantes conseguiram controlar os movimentos de abertura e fechamento através da órtese. A luva funcional foi elaborada a partir de uma luva de tecido (lycra anti-alérgica) equipada com tendões artificiais, um músculo eletromecânico e um sistema de acionamento mioelétrico. Assim, além da possibilidade de segurar e soltar objetos, os participantes apresentaram alto índice de satisfação com o uso da órtese luva funcional.

Costa et al. (2015) aponta que a falta de funcionalidade da TA pode ser uma das causas para o abandono do dispositivo. A TA tem como proposta melhorar a funcionalidade das pessoas com deficiência, caso estejam causando limitações de ordem funcional, logo não estão atendendo as necessidades desses indivíduos e não estão cumprindo o seu papel.

O desenvolvimento de um braço robótico com o objetivo de capacitar uma pessoa com tetraplegia na realização da atividade de beber de modo independente sem auxílio humano e sem quaisquer instrumentos fixados no indivíduo constituiu-se como uma solução viável e com alta confiabilidade para que o indivíduo obtivesse êxito no desempenho da tarefa. Esse resultado foi possível porque o assistente robótico guiado por um sensor de visão detecta o rosto do usuário e conduz o copo 
inteligente até a sua boca. $\mathrm{O}$ experimento inovador, além de promover a aceitação do usuário permitiu que pesquisas futuras avancem na substituição do copo inteligente atual por um copo padrão conforme a solicitação do participante tetraplégico (Goldau, Shastha, kyrarini \& Graser, 2019).

A TA além de aumentar a capacidade da pessoa com lesão medular para a realização de tarefas limitadas pela sua condição, contribui para o desenvolvimento de habilidades motoras e cognitivas. No caso de pessoas com tetraplegia, que possuem limitações devido ao comprometimento dos membros superiores (MMSS), inferiores (MMII) e órgãos pélvicos, há uma necessidade em utilizar produtos e tecnologias como cadeiras de rodas, equipamentos de transferências, recursos assistivos, sistemas de controle de ambiente, dentre outros (Cruz \& Ioshimoto, 2010). Assim, seu uso como o braço robótico constitui um avanço promissor para que o tetraplégico alcance uma melhor qualidade de vida já que são facilitadores para o desempenho das atividades cotidianas.

Em 2018, no Harvard Biodesign Laboratory, Spaulding Rehabilitation Hospital Cambridge foi desenvolvido um estudo com o objetivo de demostrar o uso da luva robótica em pessoas com lesão medular, evidenciando que o dispositivo foi eficaz para a manipulação de objetos de indivíduos com comprometimento do membro superior. Sendo, a seguir, aplicado o Toronto Rehabilitation Institute Hand Function Test (TRI-HFT) com o intuito de avaliar a capacidade de uma pessoa de manipular objetos e pesos, além de avaliar as forças que podem ser produzidas pela mão. Com base na lista de objetos de vida diária compilado dos estudos de Matheus e Dollar (2010), evidenciou-se que a luva permite que 59\% dos objetos sejam levantados com maior independência. Ademais, os participantes do estudo relataram que se beneficiariam do dispositivo para o uso doméstico na realização de atividades diárias. O TRI-HFI mostrou que a manipulação de objetos melhorou em média $33,42 \%$ em relação a pontuação máxima. Ainda, pelo fato de a luva robótica ser totalmente portátil viabilizou que o seu uso se estende-se tanto em ambientes clínicos como domésticos (Capello et al., 2018).

Yeo e Kwon (2018), propuseram determinar a eficácia do treinamento manual em cadeira de rodas em grupo para melhorar as habilidades em cadeira de rodas e desempenho qualificado do braço em adultos com lesão da medula espinhal (SCI). Os indivíduos de ambos os grupos foram testados e treinados com o Wheelchair Skills Test (WST), versão 4.1, sob a supervisão de um fisioterapeuta experiente. O WST foi realizado em um ambiente seguro e controlado. Ele mede a capacidade do usuário da cadeira de rodas em realizar uma série de habilidades necessárias à vida cotidiana. Os procedimentos do WST seguiram os descritos no Wheelchair Skills Program (WSP) Versão 4.1.

A propósito, o WST 4.1 avalia trinta e duas habilidades em usuários que operam cadeiras de rodas manualmente, sendo onze para o nível interno, doze nível comunitário e nove para o nível avançado. Foi evidenciado no estudo que as pontuações totais de habilidades em cadeira de rodas e desempenho de habilidades motoras de braço / mão melhoraram significativamente no grupo de treinamento em comparação ao grupo de controle. $\mathrm{O}$ estudo foi realizado durante oito semanas com uma frequência de três dias por semana. Foi constatado no estudo que as habilidades em cadeira de rodas realizado pelo grupo de treinamento mostrou melhorias substanciais com base nas pontuações do WST em quatro semanas. Contudo, apenas melhorias graduais foram observadas em oito semanas. Em relação ao grupo de controle não foi identificado melhorias significativas na pontuação do WST em comparação com o pré-teste (Yeo \& Kwon, 2018).

Kim, Lee e Cho (2017) apresentaram um soft wearable assistive device denominado GRIPIT com a capacidade de possibilitar que pessoas com lesão medular e paralisia nas mãos pudessem realizar a preensão de objetos. Inclusive, o GRIPIT torna viável a atividade de escrita, principalmente para indivíduos que necessitam desempenhar atividades em ambientes escolares e de trabalho. Para medir o desempenho de escrita usando o GRIPIT foram recrutadas quatro pessoas com lesão medular. Desse o modo, o estudo optou por uma luva como estrutura do dispositivo. Sendo assim, no experimento os participantes relataram que o uso do GRIPIT foi mais difícil que um dispositivo de escrita convencional, que nesses casos, consiste em fixar uma caneta em um orifício e prender a tala ao corpo. Por outro lado, os participantes evidenciaram que a 
escrita através do GRIPIT melhora a sensação da escrita e legibilidade. Ainda, o dispositivo favorece que os usuários escrevam com precisão, mesmo diante da aplicação de uma força maior. Os usuários sugeriram que o uso do dispositivo fosse simplificado, com a mudança de mecanismos de tensão. A limitação do estudo foi em relação ao tamanho da amostra.

No intuito de avaliar até que ponto as cadeiras de rodas atendiam às necessidades de atividade e participação dos usuários, bem como o nível de satisfação dos usuários com o fornecimento, reparo e manutenção dessas cadeiras de rodas. Seyi, Aston e Helen (2016) evidenciaram que para os participantes do estudo as cadeiras de rodas melhoraram sua qualidade de vida por considerarem esses dispositivos auxiliares como parte de seus corpos. Ainda, o uso da cadeira de rodas lhes proporcionou a oportunidade de realizar diversas atividades, seja como dona de casa, funcionária ou participando de atividades geradoras de renda. Quanto ao veículo foi constatado que o dispositivo de três rodas foi considerado mais fácil de manobrar em todos os tipos de terreno do que o de quatro rodas. No entanto, os usuários do veículo de três rodas informaram que em áreas rurais o indivíduo precisava ser fisicamente forte para impulsionar a cadeira de rodas morro acima ou andar em estradas irregulares. Os usuários do veículo de quatro rodas relataram que suas cadeiras de rodas não eram muito seguras e estáveis quando usadas ao ar livre, especialmente em terrenos acidentados. Como sugestão os participantes recomendaram que um veículo de três rodas dobrável deveria ser desenvolvido, pois isso contribuiria para facilitar o transporte, inclusive recomendaram o projeto de um sistema de freios para parar ou desacelerar a cadeira de rodas quando em movimento.

Em 2015 o Smart Assistive Reacher Arm (SARA) foi mais uma inovação tecnológica desenvolvido por alunos de graduação da Wayne State University. Desse modo, eles criaram um braço extensível ultraleve com reconhecimento de voz e com a capacidade de levantar cargas leves (chaves, celulares, latas de refrigerante, etc.) sem distorção. No mercado o dispositivo disponível é operacionalizado através de comando manual. Foi realizado dois experimentos, o primeiro somente com o participante tetraplégico e o segundo com a participação de mais seis jovens saudáveis. O protótipo SARA permitiu que um indivíduo com lesão medular alcançasse objetos de diferentes formas e tamanhos do mesmo modo que os participantes jovens, inclusive quanto a questão de erros no desempenho. A limitação do estudo foi em relação a participação de somente uma pessoa com lesão medular. Futuramente, a pesquisa propõe inserir deficiências semelhantes para confirmar a aplicabilidade do dispositivo (Khalid et al., 2015).

Friesen, Theodoros e Russell (2015) buscaram explorar o uso de Mobile Shower Commodes (MSCs) por adultos com lesão medular (LM), assim o objetivo era entender como adultos com LM e médicos especialistas identificam e selecionam os designs e recursos do MSC. O uso de MSCs por adultos com LM é complexo. Assim, as entrevistas semiestruturadas foram realizadas com sete adultos com SCI e com oito prescritores clínicos especialistas usando guia semiestruturado. As transcrições foram analisadas tematicamente usando a Policy, Human, Activity, Assistance and Technology, and Environment (PHAATE) como base teórica estrutural. Foi evidenciado que o desempenho MSC varia entre as atividades e durante as interações entre o usuário, o MSC, demais assistentes tecnológicos e ambientes físicos.

Com o objetivo de descrever as experiências do usuário durante a entrega do serviço MSCs, foi desenvolvido o electronic Mobile shower commode ASessment Tool (eMAST1.0). O eMAST1.0 é um questionário que foi validado recentemente para avaliar a usabilidade dos modos de exibição de celular, assim, através de uma metodologia padronizada foi possível criar escalas de medidas de saúde e de avaliação psicométrica com participantes australianos com lesão da medula espinhal (Friesen, 2019).

Cada vez mais, as pesquisas em TA para pessoas com lesão medular avançam, mas alguns desafios devem ser vencidos, pois diante de inúmeras deficiências não há uma variedade de recursos tecnológicos que atendam a todos. Ainda, deve-se ser dada a atenção a satisfação do usuário, pois muitos dispositivos assistivos podem não adequar a necessidade da clientela. Espera-se que futuramente, mais estudos sobre TA venham ser desenvolvidos e aprimorados para que mais pessoas com deficiência venham ser beneficiadas. 
Degerli, Dogu e Oksuz (2020) desenvolveram um dispositivo auxiliar impresso em 3D com o intuito facilitar a escrita. O participante tetraplégico afirmou que através do dispositivo ele foi capaz de escrever e assinar seu nome sem tremores. O dispositivo teve efeito significativo na independência. Ainda, a questão da dimensão, peso, segurança, durabilidade, simplicidade de uso e conforto foram consideradas aceitáveis pelo participante.

A atividade de escrita é fundamental no desempenho das atividades cotidianas, inclusive um estudo de caso realizado com o objetivo de apresentar o efeito do uso de tecnologia assistiva no treino de AVDs para aumento da independência funcional, foi possível verificar que um participante com tetraplegia completa de nível C6, por lesão da medula espinal, obteve ganhos funcionais em atividades promovidas com o uso de adaptações de higiene elementar (escovar dentes, pentear cabelo, passar batom, lavar o rosto e as mãos). Também foi comprovado o aumento da independência em atividades não contempladas pela Medida de Independência Funcional (MIF) como a leitura de livro, a escrita manual e o acesso ao computador (Cruz \& Ioshimoto, 2010).

Bertomeu-Motos et al. (2019) avaliaram uma environment control interface (ICE) a partir do controle de um braincomputer interfaces (BCI). A ICE possibilita que o usuário realize o controle do ambiente a partir do comando de voz. Os participantes realizaram simulações de atividades de vida diária (AVDs), ou seja, ações no ambiente simulado como beber, acender uma lâmpada ou levantar a cabeceira da cama, durante dez minutos em dois modos diferentes: AIDE usando um modelo de previsão, para reconhecer a intenção do usuário facilitando a varredura, e o modo manual, sem um modelo de previsão. O modo AIDE é baseado em uma interface multimodal capaz de analisar e extrair informações relevantes dos ambientes, bem como a identificação de habilidades residuais, comportamentos e intenções do usuário. O estudo contou com a participação de oito pessoas com diferentes patologias neurológicas. Com isso, atráves do estudo o ambiente virtual apresentado permitiu que os participantes realizassem a tarefa com o tempo médio gasto menor para o AIDE em relação ao modo manual.

Etingen et al. (2018) desenvolveram um estudo com o objetivo de avaliar as percepções dos pacientes com lesão/doenças da medular sobre unidades de environmental control units (ECUs). A pesquisa foi desenvolvida no ambiente de internação. A ECUs permite que pessoas com lesão e doença medular tenham o controle funcional do ambiente como por exemplo, operação de luzes, cama, persianas, telefone, dentre outros, a partir de vários mecanismos como ativação por voz e olhar fixo. A maioria dos participantes relataram que o dispositivo aumentou a independência, além disso, os mesmos obtiveram experiências tão positivas que recomendariam para os seus pares a ECU.

Hopper, Verdonck, Amsters, Myburg, Allan (2018) propuseram em seus estudos abordar as experiências dos usuários com os environmental control systems (ECS) no estado australiano de Queensland. Nele, todos os participantes apontaram que o dispositivo inteligente ECS aumentou a capacidade de controle independentemente dos aspectos ambientais, além de haver permitido que os participantes tivessem oportunidade de acessar a maioria das funções do celular, inclusive aplicativos. Em acréscimo, tornou-se viável que eles escolhessem quando queriam a assistência de um cuidador através do envio de mensagens. Os participantes também tiveram sentimentos de liberdade e aumento do tempo sozinho devido a esta maior independência.

Bersh (2017), em seu estudo, apresenta sistemas de controle ambiental a partir de um controle remoto para uso de pessoas com limitações motoras, ajudando para que elas realizem ligações, desliguem e ajustem aparelhos eletroeletrônicos como a luz, o som, televisores, ventiladores, abrir e fechar portas e janelas, receber e fazer chamadas telefônicas, acionar sistemas de segurança, entre outros, localizados em seu próprio ambiente. $\mathrm{O}$ controle remoto pode ser acionado de forma direta ou indireta através de acionadores localizados em qualquer parte do corpo como por exemplo: comando de voz, sopro, piscar de olhos, tração, dentre outros. Na área de TA os sistemas de controle ambiental viabilizam a promoção de maior independência no lar. 
Com o objetivo de projetar, desenvolver e avaliar soluções de acesso a produtos distantes do alcance do cadeirante sem depender da ajuda de terceiros, um estudo realizado por Rashid, Pous e Norrie (2017) pode comprovar a viabilidade dos seguintes recursos: radio frequency identification (RDIF), augmented reality (AR) e tecnologias de telas sensíveis. Os participantes foram identificados e classificados segundo a International Classification of Functioning, Disability and Health (ICF). Os participantes apresentaram diferentes graus de comprometimento, que de acordo com a ICF foram classificados nas seguintes categorias: d465 (movendo-se usando equipamento movimento deficiente da mão); d440 (uso fino da mão); d465 (movendo-se usando equipamento movimento deficiente do braço e da mão); d440 (uso fino da mão) e d445 (uso de mão e braço) (Rashid et al, 2017).

No estudo, os participantes puderam visualizar os produtos que estavam fora de seus alcances. Ademais, através das interfaces foi possível fazer compras, sem pedir ou exigir a ajuda de outras pessoas, o que contribuiu para a promoção da autonomia e independência (Rashid et al., 2017).

Ao tomar como base a MIF que tem como objetivo mensurar a capacidade funcional e independência, verifica-se que dentro dos níveis de função a independência é compreendida como a capacidade do indivíduo não necessitar de ajuda para o desempenho da atividade. Já a autonomia está relacionada com a capacidade do indivíduo tomar decisões de acordo com a sua escolha (Burnagui, Rosa \& Nascimento, 2016; Riberto et al., 2004).

No estudo de Rashid et al. (2017), os participantes alcançaram independência e autonomia dentro das suas possibilidades. Logo, a TA cumpre o seu papel à medida que amplia a habilidade funcional deficitária da pessoa com deficiência e permite que a mesma alcance uma melhor qualidade de vida e inclusão social. (Bersh, 2017).

Folan, Barclay, Cooper e Robinson (2015), buscaram compreender as experiências de clientes com tetraplegia experimentando tecnologias assistivas para acesso a computador em diferentes etapas de um serviço público de reabilitação. No estudo ficou evidente que a tecnologia assistiva criou benefícios para os participantes, auxiliando na superação de barreiras físicas. Além disso, o uso da internet para se socializar e completar diariamente tarefas, permitiu que os participantes ganhassem um senso de controle sobre suas vidas, aumentando sua independência e aprimorando seus sensos de autoeficácia.

Os estudos apresentados tem apontado que a TA pode ser um grande aliado para a pessoa com lesão medular alcançar a sua autonomia e independência. Quanto mais investimentos houver na área de TA, maior será a possibilidade desses indivíduos serem incluído socialmente, já que os dispositivos tecnológicos são projetados no intuito de viabilizar os usuários em suas atividades cotidianas melhorando a sua qualidade de vida.

\section{Conclusão}

A partir da revisão integrativa pode-se observar que a TA tem um papel fundamental para o desempenho das atividades cotidianas de pessoas com lesão medular. Ao melhorar as habilidades funcionais das pessoas com lesão medular esse recurso se torna indispensável para que esses indivíduos tenham êxito em tarefas tanto básicas como complexas. Vale ressaltar, que nem todo paraplégico ou tetraplégico vai alcançar a meta máxima de funcionalidade, já que diante de sua condição várias questões devem ser analisadas que vão desde o nível de lesão medular até a adequação do dispositivo tecnológico de acordo com a necessidade dos usuários. Nos estudos também ficou evidente que as pessoas com lesão medular alcançaram autonomia funcional com o uso da TA, além do sentimento de liberdade relatos por alguns deles. A limitação do estudo foi em relação ao pequeno número de artigos sobre a temática, inclusive foi possível perceber que todos os estudos encontrados são internacionais, o que desperta para o maior desenvolvimento de pesquisas nacionais nessa área. 


\section{Referências}

Angelina, C., \& Soligo, S. (2016). Lei Brasileira de Inclusão da Pessoa com Deficiência - Comentada / Joyce Marquezin Setubal, Regiane Alves Costa Fayan (orgs.). Campinas: Fundação FEAC, 2016. ISBN: 978-85-69685-03-6 Pessoas com deficiência - Direitos Humanos Lei Brasileira de Inclu.

Bersch, R. (2017). Tecnologia Assistiva SNPD. 1. https://www.assistiva.com.br/Introducao_Tecnologia_Assistiva.pdf.

Bertomeu-Motos, A., Ezquerro, S., Barios, J. A., Lledó, L. D., Domingo, S., Nann, M., Martin, S., Soekadar, S. R., \& Garcia-Aracil, N. (2019). User activity recognition system to improve the performance of environmental control interfaces: A pilot study with patients. Journal of NeuroEngineering and Rehabilitation, 16(1), 1-9. https://doi.org/10.1186/s12984-018-0477-5.

Burnagui, J. G., Rosa, M. P. da., \& Nascimento, G. C. C. (2016). Autonomia e independência: percepção de adolescentes com deficiência visual e de seus cuidadores. Revista de Terapia Ocupacional da Universidade de São Paulo, 27(1), 21-28. http://www.revistas.usp.br/rto/article/view/104407/114556.

Cappello, L., Meyer, J. T., Galloway, K. C., Peisner, J. D., Granberry, R., Wagner, D. A., Engelhardt, S., Paganoni, S., \& Walsh, C. J. (2018). Assisting hand function after spinal cord injury with a fabric-based soft robotic glove. Journal of NeuroEngineering and Rehabilitation, 15(1), 1-10. https://doi.org/10.1186/s12984-018-0391-x.

Civil, C. (2019). Presidência da República. 1-13.

Costa, C. R. da., Ferreira, F. M. R. M., Bortolus, M. V., \& Carvalho, M. G. R. (2015). Dispositivos de tecnologia assistiva: fatores relacionados ao abandono. Cadernos de Terapia Ocupacional da UFSCar, 23(3), 611-624. https://doi.org/10.4322/0104-4931.ctoar0544.

Cruz, D. M. C. da., \& Ioshimoto, M. T. A. (2010). Tecnologia Assistiva Para As Atividades De Vida Diária Na Tetraplegia Completa C6 Pós-Lesão Medular. $177-190$.

Decreto $n^{o} 5296$ de 02 de dezembro de 2004,2004. http://www.planalto.gov.br/ccivil_03/_ato2004-2006/2004/decreto/d5296.htm.

Degerli, Y. I., Dogu, F., \& Oksuz, C. (2020). Manufacturing an Assistive Device With 3D Printing Technology- a Case Report. Assistive Technology, 00(00), 1-5. https://doi.org/10.1080/10400435.2020.1791278.

Etingen, B., Martinez, R. N., Vallette, M. A., Dendinger, R., Bidassie, B., Miskevics, S., Khan, H. T., Cozart, H. T., Locatelli, S. M., \& Weaver, F. M. (2018). Patient perceptions of environmental control units: experiences of Veterans with spinal cord injuries and disorders receiving inpatient VA healthcare. Disability and Rehabilitation: Assistive Technology, 13(4), 325-332. https://doi.org/10.1080/17483107.2017.1312574.

Folan, A., Barclay, L., Cooper, C., \& Robinson, M. (2015). Exploring the experience of clients with tetraplegia utilizing assistive technology for computer access. Disability and Rehabilitation: Assistive Technology, 10(1), 46-52. https://doi.org/10.3109/17483107.2013.836686.

Friesen, E. L. (2019). An introduction to the electronic Mobile shower commode ASessment Tool (eMAST). https://www.researchgate.net/publication/331260722_An_introduction_to_the_electronic_Mobile_shower_commode_ASessment_Tool_eMAST.

Friesen, E. L., Theodoros, D., \& Russell, T. G. (2015). Use, performance and features of mobile shower commodes: Perspectives of adults with spinal cord injury and expert clinicians. Disability and Rehabilitation: Assistive Technology, 10(1), 38-45. https://doi.org/10.3109/17483107.2013.832413.

Galvão, T. A. F. (2009). Tecnologia assistiva para uma escola inclusiva: apropriação, demanda e perspectivas. 346. https://repositorio.ufba.br/ri/handle/ri/10563.

Goldau, F. F., Shastha, T. K., Kyrarini, M., \& Graser, A. (2019). Autonomous multi-sensory robotic assistant for a drinking task. IEEE International Conference on Rehabilitation Robotics, 2019-June, 210-216. https://doi.org/10.1109/ICORR.2019.8779521.

Hooper, B., Verdonck, M., Amsters, D., Myburg, M., \& Allan, E. (2018). Smart-device environmental control systems: experiences of people with cervical spinal cord injuries. 13(8), 724-730. https://doi.org/10.1080/17483107.2017.136959.

Khalid, U., Conti, G. E., Erlandson, R. F., Ellis, R. D., Brown, V., \& Pandya, A. K. (2015). Voice-activated lightweight reacher to assist with upper extremity movement limitations: A case study. Assistive Technology, 27(2), 112-120. https://doi.org/10.1080/10400435.2014.970676.

Kim, B., In, H., Lee, D. Y., \& Cho, K. J. (2017). Development and assessment of a hand assist device: GRIPIT. Journal of NeuroEngineering and Rehabilitation, 14(1), 1-14. https://doi.org/10.1186/s12984-017-0223-4.

Meneses, K. V. P. de., Rocha, D. N., Corrêa, M. F. S., \& Pinotti, M. (2008). Testes preliminares de um protótipo de órtese funcional para mão. Revista de Terapia Ocupacional Da Universidade de São Paulo, 19(3), 193-201. https://doi.org/10.11606/issn.2238-6149.v19i3p193-201.

Meneses, K., Rocha, D., Júnior, F., Sono, T., Oliveira, A., \& Pinotti, M. (2012). Aplicação de uma órtese funcional para mão em indivíduos com lesão do plexo braquial* Application of a functional hand orthosis in individuals with brachial plexus injuries. 34-43.

Ministério da Saúde. Secretaria de Atenção à Saúde. Departamento de Ações Programáticas Estratégicas. (2015). Diretrizes de Atenção à Pessoa com Lesão Medular Diretrizes de Atenção.

Osuagwu, B. A. C., Timms, S., Peachment, R., Dowie, S., Thrussell, H., Cross, S., Shirley, R., Segura-Fragoso, A., \& Taylor, J. (2020). Home-based rehabilitation using a soft robotic hand glove device leads to improvement in hand function in people with chronic spinal cord injury:a pilot study. Journal of NeuroEngineering and Rehabilitation, 17(1), 1-15. https://doi.org/10.1186/s12984-020-00660-y.

Rashid, Z., Pous, R., \& Norrie, C. S. (2017). An independent shopping experience for wheelchair users through augmented reality and RFID. Assistive Technology, 31(1), 9-18. https://doi.org/10.1080/10400435.2017.1329240. 
Research, Society and Development, v. 10, n. 8, e0210815387, 2021

(CC BY 4.0) | ISSN 2525-3409 | DOI: http://dx.doi.org/10.33448/rsd-v10i8.15387

Riberto, M., Miyazaki, M. H., Jucá, S. S. H., Sakamoto, H., Pinto, P. P. N., \& Battistella, L. R. (2004). Validation of the Brazilian version of Functional Independence Measure. Acta Fisiátrica, 11(2), 3-7. https://doi.org/10.5935/0104-7795.20040003.

Rocha, E. F., \& Castiglioni, M. D. C. (2005). Reflexões sobre recursos tecnológicos: ajudas técnicas, tecnologia assistiva, tecnologia de assistência e tecnologia de apoio. Revista de Terapia Ocupacional Da Universidade de São Paulo, 16(3), 97-104. https://doi.org/10.11606/issn.2238-6149.v16i3p97-104.

Seyi, A., Aston, N., \& Helen, B. (2016). Locally manufactured wheelchairs in Tanzania - Are users satisfied? African Health Sciences, 16(4), $1174-1181$. https://doi.org/10.4314/ahs.v16i4.37.

Soares, C. B., Hoga, L. A. K., Peduzzi, M., Sangaleti, C., Yonekura, T., \& Silva, D. R. A. D. (2014). Revisão integrativa: conceitos e métodos utilizados na enfermagem. Revista Da Escola de Enfermagem Da U S P., 48(2), 335-345. https://doi.org/10.1590/S0080-623420140000200020.

World Health Organization. (2011). Summary World Report On Disability. World Health, 1-24. http://www.larchetoronto.org/wordpress/wpcontent/uploads/2012/01/launch-of-World-Report-on-Disability-Jan-27-121.pdf.

Yeo, S. S., \& Kwon, J. W. (2018). Wheelchair Skills Training for Functional Activity in Adults with Cervical Spinal Cord Injury. International Journal of Sports Medicine, 39(12), 924-928. https://doi.org/10.1055/a-0635-0941.

Yoo, H. J., Lee, S., Kim, J., Park, C., \& Lee, B. (2019). Development of 3D-printed myoelectric hand orthosis for patients with spinal cord injury. Journal of NeuroEngineering and Rehabilitation, 16(1), 1-14. https://doi.org/10.1186/s12984-019-0633-6. 